\section{A Practical Approach for Gender- and Diversity-informed Geomedia Education for Teachers in Training}

Gl_Forum 2016, Vol.1

Page: 269-281

Full Paper

Corresponding Author:

nicole.ferber@sbg.ac.at

DOI: 10.1553/giscience2016_01_s269

Nicole Ferber, Helena Atteneder, Thomas Jekel and Sandra Stieger

Salzburg University, Austria

\begin{abstract}
At the University of Salzburg, a new module links science topics, pedagogy and school practice for students in teacher-training. In a pilot project within this module, an iterative process of curriculum development for the topic of gendered spaces in the city was developed. The approach is based on everyday geomedia use and its implications for the construction of feminine/masculine spaces. This paper reports on the process of linking scientists, student teachers and secondaryschool students, both showing the feasibility of the approach and giving indications of its effectiveness with regard to diversity-sensitive learning.
\end{abstract}

\title{
Keywords:
}

automated geomedia, education, gender, spatial citizenship,teacher training

\section{Setting - the Austrian teacher-training curricula and strategies for practical implementation}

Within teacher training in the scientific domain, one of the main difficulties is providing the link between scientific education and its transfer to the classroom in secondary education. In many cases, trainees complain about minimal transferability between theoretical science education at universities and classroom implementation. Austrian universities have a reasonable proportion of pedagogical and school practice in their teacher-training curricula. However, the content of subject education and pedagogy have not been linked properly. At the same time, universities have been involved in a wide range of forms of cooperation with Science and Education, which have been funded for the purpose of linking science and secondary education through the involvement of students in real-world science projects. Geomedia use has been at the forefront of this development (Hennig \& Vogler, forthcoming; Jekel, Koller, \& Strobl, 2012; Vogler, Hennig, \& Lindner-Fally, 2015). In a number of initiatives at the University of Salzburg, various models were developed that changed the perspective from that of transferring science results to secondary education to approaches that provide mutual interest to both the research domain and the secondary 
education community. Again, the findings of these instances of co-operation have not been reflected widely in everyday teacher training. As a result, following a directive from the vicerector for teaching, the University of Salzburg devised a module combining pedagogy and practice (Universität Salzburg, 2015, see fig. 1).

\section{Themed Module: Pedagogy - School Practice - Science (12 ECTS)}

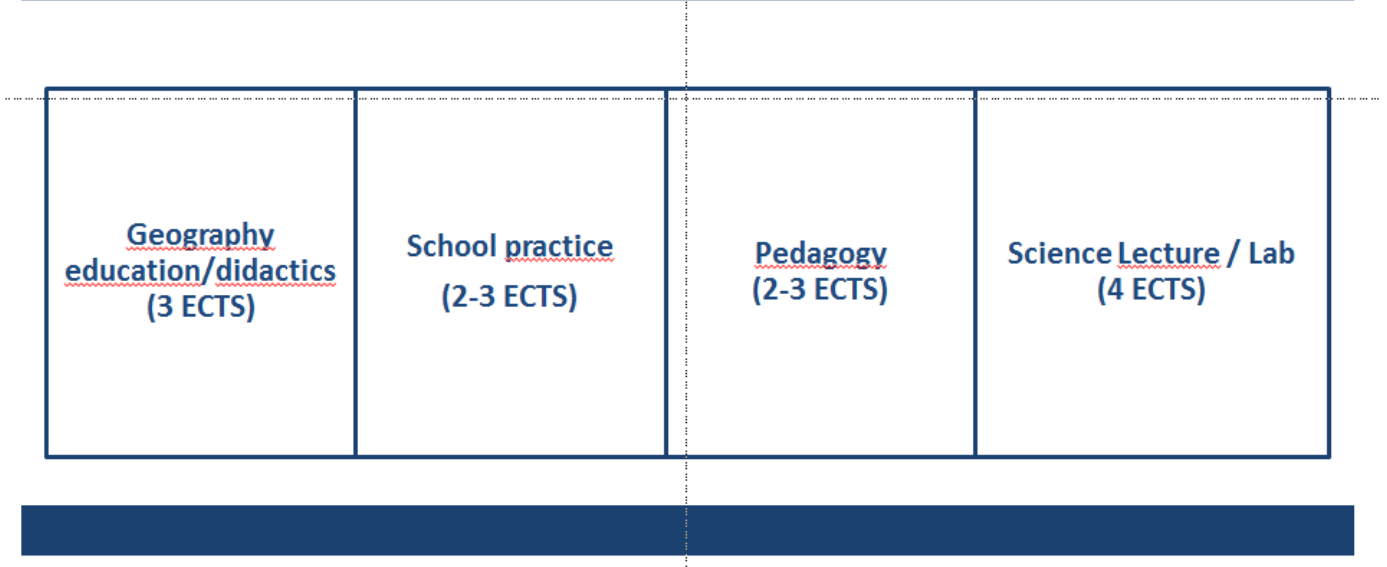

Figure 1: Pedagogic/practical module: Pedagogy - School Practice - Science (Universität Salzburg, 2015). (ECTS = European Credit Transfer System)

Within the pedagogic/practical module, students have to pass a series of interlinked interdisciplinary lectures/labs. In a subsequent step, the theoretical basis taught in several teacher-training courses is transferred to real-world school use, implemented practically in several lessons in secondary education. The themed modules therefore allow a link between teacher training and science education, providing valuable information for educators on practical implementation strategies in schools. Additionally, this approach allows teachers to participate in current scientific projects and provides students in teacher training with an informed practice.

The Gender and Geomedia course was a pilot course for the pedagogic/practical module at the University of Salzburg. It was run in the winter semester of 2015/16 and will be the model used for further modules across all subjects of teacher training. It is based on theoretical considerations that link feminist and queer dimensions in education with geomedia, with communication theory and with pedagogy (De Luca, Ferber, Atteneder, \& Jekel, 2015), and was co-funded by the IMST Initiative of the Austrian Ministry of Education and Women (https://www.imst.ac.at/). 


\section{Gender dimensions in geography education - combining gender and geomedia}

Based on the theses of a (geo-)digitalized society (GISociety) and of mediatized worlds, this paper discusses the importance of integrating diversity and gender dimensions (and hence of addressing inequalities in general) in educational approaches in geography education. When we use the term "media", the underlying concepts refer mostly to technical media communication that extend our possibilities to communicate spatially and temporally. However, recently-developed geomedia combine information and communication technologies with geographical information. In recent years, several developments have led to what we now call geomedia:

- The increasing pervasion of society by media technologies, from printing to new and ubiquitous forms of networked connectivity. According to Steinmaurer, new systems of uninterrupted mediatized connectivity imply certain aspects of hegemonic power structures (Steinmaurer, 2014). Mediatization is understood as a concept that is used in order "to carry out a critical analysis of the interrelation between the change of media and communication, on the one hand, and the change of culture and society on the other" (Hepp \& Krotz, 2014).

- Emerging Geoinformation (GIS) technologies, starting with the Canada Land Inventory in the early 1960s by the Department of Forestry and Rural Development (Agriculture and Agri Food Canada).

- The advent of Web 2.0 technology accompanied by increased individual mobility connected and reinforced by new "smart" spatially-enabled mobile devices, i.e. smartphones (Strobl, 2014; Thielmann, van der Velden, Fischer, \& Vogler, 2012)

- Individualization - the shift from "mobile privatization to mobile individualization" (Steinmaurer, 2014, p. 98), questioning the role of families both as the smallest social units in our society and as its social centre. The family as an institution of socialization is one amongst many factors, for socialization and "the appropriation strategies for media technologies are increasingly connected to the mobile individual rather than to the family as an entity that decides how media are to be incorporated into everyday life routines" (Steinmaurer, 2014, p. 99).

These developments are prerequisites for the development of the "GISociety". The everyday use of spatially-enabled devices is linked to dissolving boundaries between consumers and producers of (geo)information. In recent years, an increasing number of easy-to-use and open-source mapping tools have promoted emerging research domains such as Citizen Science, Volunteered Geographic Information, Neogeography and Open Government Initiatives. These research domains emphasize that mapping is easy and possible for everyone, explicitly for lay people (Haklay, 2013). According to such an optimistic perspective, maps can be seen as a tool for (self-)expression. Furthermore, it is assumed that the (geo)web leads to greater participation and greater democracy (Haklay, 2013). Nevertheless, the rise of critical cartography, which assumes that cartographers do not produce "objective" maps that show "accurate reality", implies that the lay person can become a (specialist) cartographer of local and regional geographies. In fact, maps imply 
hegemonic power relations, and with the rise of geomedia opportunities for empowerment arise since the consumer becomes the prosumer (Leszczynski \& Elwood, 2015).

Therefore, space cannot be understood conceptually simply as a "container", defined by its accurate GNSS-Position. Space in the constructivist tradition is, furthermore, socially constructed and therefore altered in a discursive process. According to the constructivist perspective, space is "made" by every single individual; it is a product of the appropriation of space (Wardenga, 2002). With geomedia, new means to visualize time and space support the appropriation of space and spatial perception (Ferber \& Jekel, 2013). Geomedia are part of the significant and fundamental changes in our communication and visualization, and have an important impact in decision-making processes in mediatized societies.

Education needs to adapt to these developments of a (geo)mediated world. This is where the concept of Education for Spatial Citizenship comes into play. The concept is rooted in the emancipatory domain of education, linking geoinformation to secondary education. An Education for Spatial Citizenship aims to empower lay users in their everyday appropriation of space through geomedia (Gordon, Elwood, \& Mitchell, 2016; Gryl \& Jekel, 2012; Gryl, Jekel, \& Donert, 2010; Jekel, Gryl, \& Schulze, 2015).

Spatial Citizenship addresses three main areas of competence, namely technological competences, competences of reflexivity and reflection, and competences of communication/ participation. Traditionally, the use of GIS in secondary education focused mainly on the technological domain. This has changed through the advent of apps and webbased innovations, which additionally allow lay users to prosume geomedia and take part in decision-making processes (Gryl \& Jekel, 2012).

Concepts of difference and diversity (e.g. gender), however, have not featured prominently in geomedia education so far. A first theoretical draft linking feminist and queer dimensions in education with geomedia, with communication theory and with pedagogy was drawn up by De Luca et al. (2015). This draft was based mainly on gender representations within geomedia and did not delve into data structures: "The intersections of feminist GIS with the concept of Spatial Citizenship is seen in connection with the ability of a spatial citizen to participate in society, in terms of the interpretation and critical reflection on spatial information, the communication with the assistance of spatial representations, and the expression of location-specific opinions using geomedia" (De Luca et al., 2015, p. 280).

It is becoming obvious that specific gender gaps in the production and consumption of maps are relevant. Based on empirical research, the description of the world (i.e. making maps) is still mainly dominated by males, and women contribute only marginally to projects such as OpenStreetMap (Haklay \& Budhathoki, 2010; Pavlovskaya \& Martin, 2007; Steinmann, Häusler, Klettner, Schmidt, \& Lin, 2013).

Stephens \& Rondinone (2012) discuss how men are still the primary constructors of the world because women are not willing or not able to volunteer geographical information. From a social constructivist perspective, structural reasons for the exclusion of women in decision-making processes should be questioned. What are the reasons for exclusion, and who is excluding whom? Basically, the first gender theories distinguished between a biological "sex" and socially constructed "gender". Butler (2004) goes one step further in 
deconstructing even the biological sex. In dissolving the binary system of men/women into a multi-layered concept as suggested from a queer perspective (Elder, 1999; Shlasko, 2005), gender becomes culturally and socially (discursively) constructed, and the natural character of the male/female dichotomy is opposed. Nevertheless, we have to keep in mind that gender as a fluid category works alongside other social categories. Categories such as race, class and age (to name but a few) co-exist alongside the category gender. The normalization in binaries like man/woman is discussed mostly without the social context of class and age, which add additional inequalities. The concept of intersectionality (Winker \& Degele, 2010) provides the theoretical framework to analyse different categories of inequality and relational identities from a multitude of perspectives.

To conclude, from a social constructivist perspective, gender, maps and space are socially constructed (Wastl-Walter, 2010) and produced in a discursive way. The implementation of this perspective needs to be introduced in the classroom.

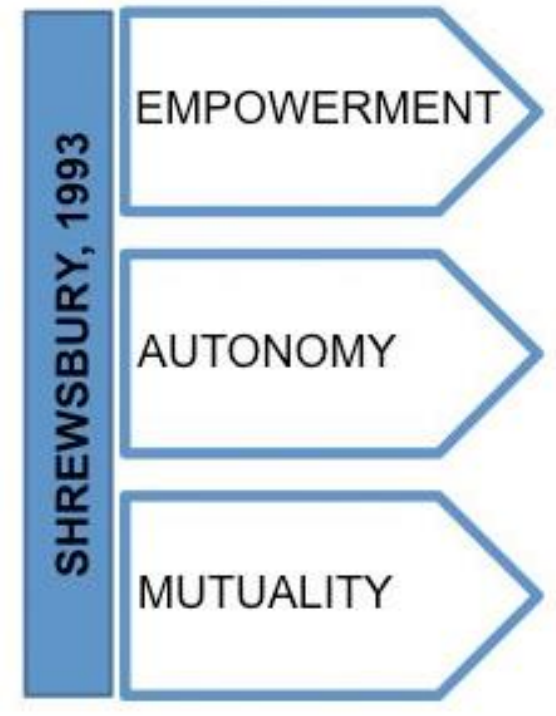

RELATIONAL THINKING

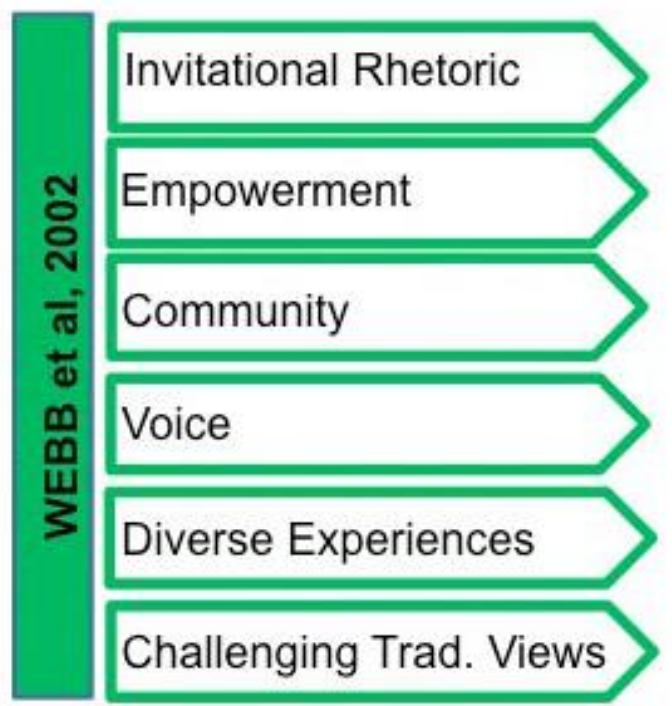

NON-HIERARCHICAL RELATIONS

Figure 2: Feminist pedagogies (based on (Shrewsbury, 1993; Webb, Allen, \& Walker, 2002)

Figure 2 shows two different approaches to feminist pedagogies. Shrewsburys' (1993) perspective is argued from a relational thinking perspective were the teacher student relationship is centred on empowerment, autonomy and mutuality. Web, Allen and Walker (2002) refine the feminist pedagogical approach to non-hierarchical relations based on invitational rhetoric, empowerment, community, voice, diverse experiences and challenging traditional views. 
To achieve these in the field of geomedia, two main strategies are deemed necessary: a queering of data (Leszczynski \& Elwood, 2015) and diversity-sensitive visualizations, allowing for diverse experiences and therefore challenging traditional views. The project described here, while following a traditional "feminist-perspective", used ideas from queer theory developing a meaningful question connected to real world issues to guide the secondary students' research work.

\section{Implementation}

The process of implementation and the realization of the course goals will be described below. The course "Geomedia and Gender" aimed first of all to:

- generate basic theoretical knowledge on gender and geomedia by introducing students to relevant scientific literature and critical reading of it

- prepare learning environments for secondary students focusing on the central theme of gender and geomedia, and on more specific gendered spaces of fear versus feelgood spaces; there was a particular focus on comprehensibility for pupils (grade 7, age 16 to 17$)$

- prepare lessons with an easy-to-use web-based mapping tool (ArcGIS-Online) to be taught with the help of geomedia in secondary schools.

\section{Student-teacher Activities}

The first two sessions were used to give an overview and theoretical input by the course instructors, including basic gender, feminist and queer theory, critical cartography and theories of space. The overview focused on the paradigm of social constructivism and on gendered forms of the appropriation of time and space. The third session was used to introduce the students to ArcGISonline. Most of the students had already used the cloudbased software in other courses and were familiar with the basic concept. The main aims of the introduction to the software were to demonstrate its use in gathering data and to show how to visualize it with ArcGISonline. The principles of data collection and visualization were demonstrated with sample data to show the structure of very simple data models.

During the next couple of sessions, the student teachers gained additional theoretical knowledge via self-directed learning. The course was accompanied by a virtual learning tool (elearn.sbg.ac.at), which documented the course and provided literature. Every week, students were required to read a new article or book chapter and had to post critical comments to a discussion forum. These comments were collected and presented in a face-toface discussion moderated by the students. Every student was responsible for coordinating at least one session during the course, and for one input presentation based on a given article. Overall, active participation and the discussions during the sessions helped the students to acquire a deeper understanding of the scientific literature and the basic concepts. 


\section{Gender and Geomedia: Gendered Spaces in the city}

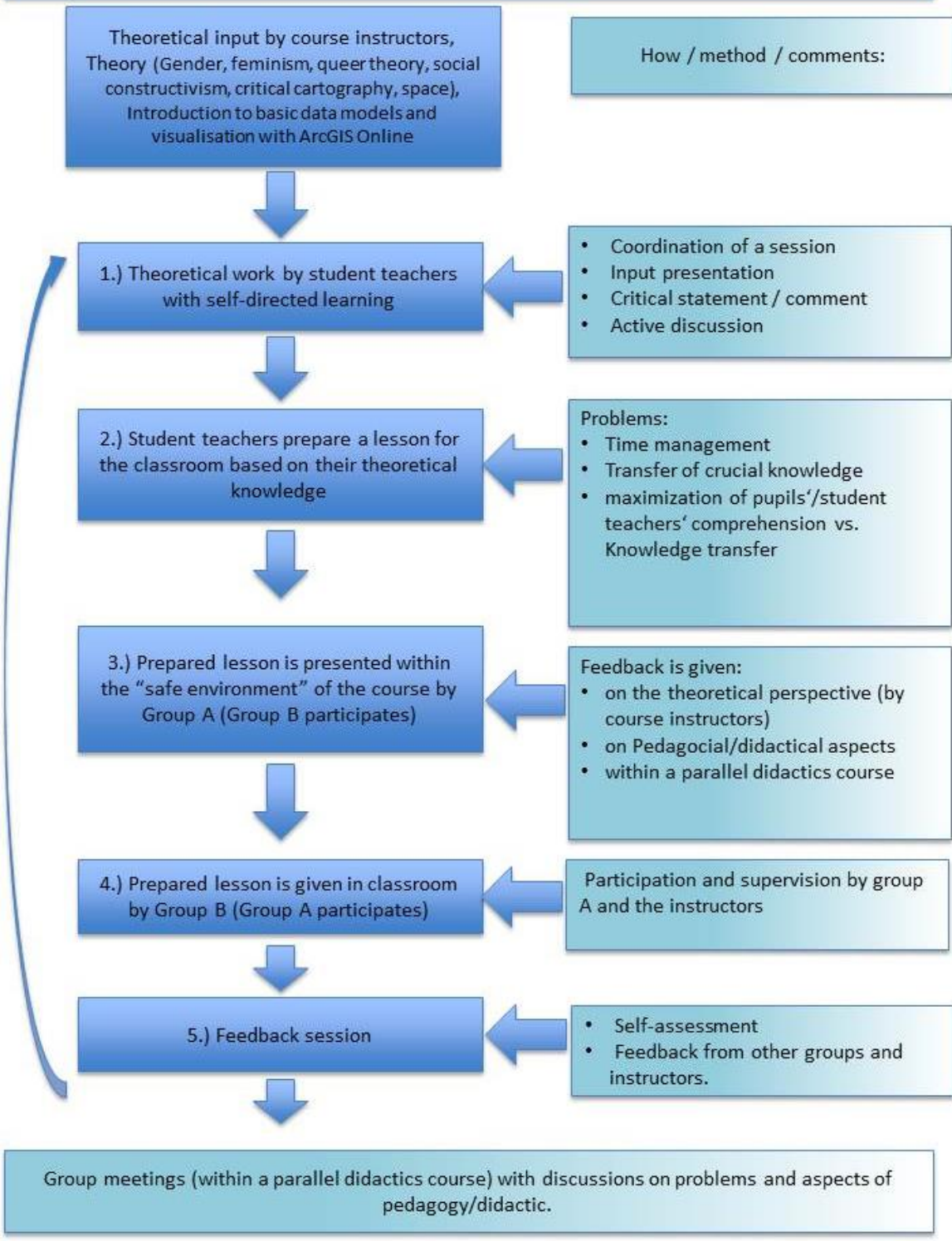

Figure 3: Structure of the course

In the next step, the student teachers had to prepare lessons for the classroom based on the theoretical input of the earlier sessions and the literature discussed. The lesson plans included a chronological structure of pupil and student-teacher activities, as well as a timeline, methods and step-by-step teaching objectives. In addition, the trainees had to create adequate teaching materials for the planned lessons and to justify their choice of methods. 
An iterative process allowed quality control and a smooth practical transfer of the theories by the student teachers to the pupils.

A 5-step process based on theoretical work and group work, as shown in the flow chart (Figure 3), allowed the student teachers to prepare the learning environments. The underlying goal was for them to teach pupils the possibilities of communication with maps with the help of geomedia (ArcGISonline). The main topic here was to map spaces of emotions: the Common-Sense World ${ }^{1}$ of young people makes it possible to show the social construction of space as an expression of certain user and interest groups.

The main difficulties that occurred within the student teachers' activities were time management and focusing on the crucial core of the content in conjunction with maximum comprehension by the pupils. The trainees prepared the lessons in groups and (step 3) presented them within the "safe environment" of the university. The course instructors, an instructor from a parallel pedagogy course, as well as course participants gave feedback on theoretical and pedagogical aspects of the lessons. In the following step, the prepared lesson was delivered in the classroom. Afterwards, a feedback session (step 5) within the framework of the university course evaluated the outcome of the practical implementation. Feedback and the students' reflective analysis of questions such as time management, challenges and coping with unexpected events were supported by the instructors and fellow participants.

\section{Secondary-Student Activities}

The teaching-practice sessions were delivered at Borromäum highschool in Salzburg city to a class of 18 male students (aged 16-17). For the highschool students, these sessions amounted to three 50-minute lessons and a half day of project work.

Two single lessons were devoted to basic gender theory and the theory of the construction of space. In the third lesson, a short introduction to ArcGISonline was given, based on existing tutorials with example data sets. Due to time constraints, the data model was devised by the student teachers and not by the pupils.

For the project element, the secondary students were given the task of mapping spaces of fear and feel-good spaces. In the first step, they were asked to do this from their own (male) perspective. In the next step, they were asked also to map what they perceived to be female spaces of fear and feel-good spaces. Thus each marker point included both a male and a female perception (see Figure 4).

\footnotetext{
1 The term "Common-Sense World" is used in a sociological sense and refers to Gurwitsch's discussion of Schütz's “Alltagswelt als soziale Wirklichkeit” (“Common-Sense World as Social Reality”) (Gurwitsch, 1962).
} 


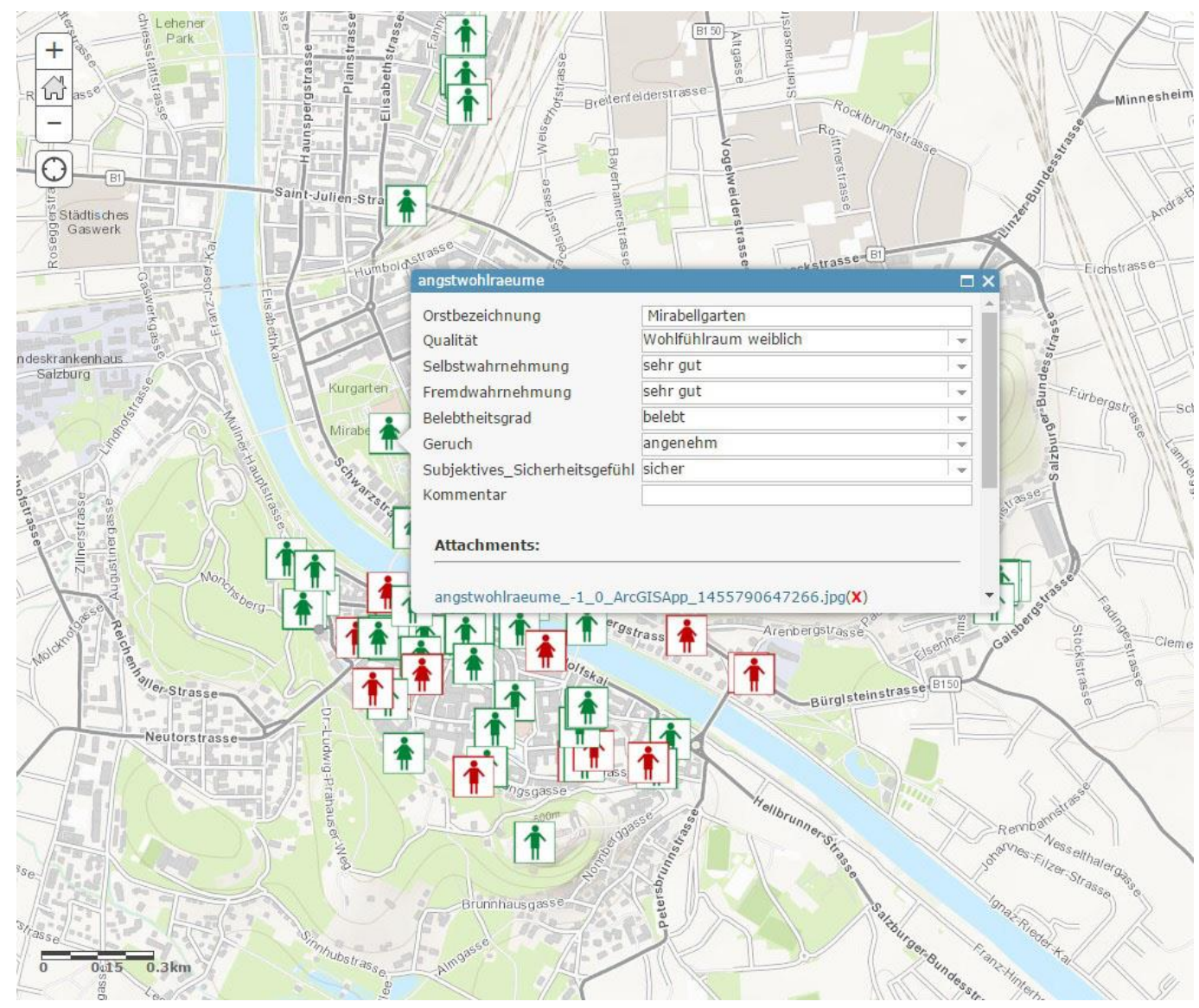

Figure 4: "Gendered spaces of fear versus feel-good spaces" (Borromäum secondary students' map)

In the discussion which followed, the dominant, traditional gender roles were challenged by both the student teachers and the secondary school students. Because of the double values assigned to each point (i.e. to each place initially selected by the male participants as being dangerous or feel-good for men or for women; because the participants were all male, the latter were evaluated from a necessarily imagined female perspective), it became apparent that the initial values allocated by participants followed traditional stereotypes. When revisiting the map, students discovered the stereotyping for themselves and argued for the need for the target groups themselves to carry out the mapping. A further subject of discussion was that the points selected followed a homogeneous pattern. A possible reason for this discussed by the student teachers and the school students was the homogeneous structure of the mapping group itself (male, close in age, similar social and cultural backgrounds ...). 


\section{Evaluation of the practical implementation by the student teachers}

The Geomedia and Gender course was accompanied by a parallel course in pedagogy in which the practical teaching experience was reflected upon and evaluated. This course was led by an experienced teacher who was also present during the classroom activities and feedback sessions.

Before the student teachers held their lessons at the school, possible areas for particular observation were discussed. On the base of an initial draft, participants together developed a common concept for a focused collegial observation. The main interest of the students was on the appreciation of gender dimensions transmitted through language, including teachers' and pupils' language use. The overall objective was to support self-competence, which includes moral concepts such as gender sensitivity (Euler \& Hahn, 2014). The student teachers had to write a self-reflective account of the lesson held. The subsequent evaluation showed that the main obstacles were time management and coordination within the teaching team. Due to their number, trainees had to co-teach the lessons in groups of up to four. For the student teachers, not only the planning process but also the limited space in the classroom was a challenge. However, the structural school reforms in Austria increasingly require the capability to work in teams. For instance, in New Secondary Schools (Neue Mittelschule) the main subjects are co-taught by two teachers. In the future, there will be a greater need for further teacher training regarding team-teaching. Additionally, it was surprising that before attending the module most of the student teachers did not recognize the relevance of gender-sensitive teaching. Under these circumstances, it is doubtful whether gender-sensitive teaching can be applied to school lessons if it is not recognized by young teachers.

This observation was also confirmed by the behaviour of the pupils during the practical teaching experience at school: the majority of pupils reacted negatively on the announcement of the gender topic. Clearly the pupils did not initially recognize their need for more information regarding the topic. In particular, their concept of gender-sensitivity was limited to the need for gender sensitive language (The use of gender neutral language modification in languages with grammatical gender like German, French and Spanish is much more difficult and is widely criticized by conservatives). Nevertheless, during the lesson growing interest was observed.

On the other hand, the anonymous written reflections of the student teachers on their own school experiences regarding gender-based preferential or discriminated treatment highlighted the need for action. Behavioural stereotypes, such as that girls are well-behaved, diligent and ambitious, while boys are inattentive, annoying and restless, were confirmed by all student teachers. The acceptance of misbehaviour by boys was much higher than for girls. Additionally, girls are likely to be discriminated against in specific (scientific) subjects, as the teachers' expectation of their performance is much lower than for boys. The gap between the student teachers' experiences at school and their attitude regarding gender-sensitive lessons clearly demonstrates a need for action. 
In conclusion, reflection on the practical teaching experience confirmed that gender-training is relevant and highly necessary for teacher training and further education. Sustainable overarching changes in self-competence regarding gender-sensitivity cannot be attained within one themed module, but the module can serve as a starting point for further development in this area.

\section{Summary}

The student teachers had to ensure that the gender component was taken into account in every aspect of the development process for the learning environments leading to the development of the map itself. This turned out to be quite challenging. Instead of teaching just knowledge that was ready to be reproduced, the student teachers had to think of genderrelated aspects of space from relational and individual points of view. It turned out that the relational concepts of space and the social construction of gender and space taught earlier at university did not prepare the trainees adequately to teach the concepts themselves. Quite some time was therefore invested by the course instructors to transfer basic knowledge of such things as relational concepts of space as well as the social construction of gender and place and their interrelation.

First of all, the student teachers developed a data model that considered attributes which could be assigned to spaces of fear and feel-good spaces. As the gender component specifically needed to be integrated, the students decided to develop four qualities of spaces of fear and feel-good spaces which reproduce gender binaries (male space of fear/male feelgood space, and female space of fear/female feel-good space). Other attributes which described these spaces referred to how the participants perceived the spaces as opposed to how others (i.e. women) would perceive them (self-perception vs. external perception). Since we had a class of 18 male secondary students, they had to change perspective, adopting an external one, in order to decide how a woman or a girl might have categorized a place. By taking a closer look at the points added (the liveliness of the street/place, its smell and the subjective sense of security), a discussion about feelings in terms of self-perception and the allocation of a different external perception was possible. Gender stereotypes were uncovered and the secondary students questioned their opinions.

On a more general level, the pilot project showed two main results:

- Gender-sensitivity is a concept that has been reduced to gender-sensitive language, both for students in secondary school as well as for students in higher education. Changes in subject-specific approaches to gender and diversity are called for that look into diversity and intersectionality and make the topic of inequality of wider concern.

- Within the topic of gender and geomedia, the current project could support a sensitization of both secondary and post-secondary students. This could be linked to the conception of a political subject as described by Gordon et al. (2016).

Future projects should be based on these two main findings. 


\section{Acknowledgements}

This publication has been co-financed by IMST, an Initiative of the Austrian Ministry of Education and Woman (BMBF) (www.imst.ac.at), as well as by gendup, the centre for equal opportunities at the University of Salzburg.

\section{References}

Agriculture and Agri Food Canada. Canada Land Inventory (CLI). Retrieved from http://sis.agr.gc.ca/cansis/nsdb/cli/index.html

Atteneder, H., Ferber, N., De Luca, N., \& Jekel, T. (2015). Beiträge feministischer Theorien zu einer Education for Spatial Citizenship. GW-Unterricht, 137(1), 14-24.

De Luca, N., Ferber, N., Atteneder, H., \& Jekel, T. (2015). Feminist and Queer Approaches to Education for Spatial Citizenship. GI_Forum - Journal for Geographic Information Science, 2015(1), 272-282. doi:doi:10.1553/giscience2015s272

Elder, G. S. (1999). 'Queerying' Boundaries in the Geography Classroom. Journal of Geography in Higher Education, 23(1), 86-93. doi:10.1080/03098269985632

Euler, D., \& Hahn, A. (2014). Wirtschaftsdidaktik (3., aktualisierte Aufl. ed.). Berne: Haupt.

Ferber, N., \& Jekel, T. (2013). Visualising the Re-Production of Space with Multi-Layer Maps Paper presented at the GI_Forum 2013, Wien.

Gordon, E., Elwood, S., \& Mitchell, K. (2016). Critical spatial learning: participatory mapping, spatial histories, and youth civic engagement. Children's Geographies, 1-15. doi:10.1080/14733285.2015.1136736

Gryl, I., \& Jekel, T. (2012). Re-centring Geoinformation in Secondary Education: Toward a Spatial Citizenship Approach. Cartographica, 47(1), 18-28.

Gryl, I., Jekel, T., \& Donert, K. (2010). GI and Spatial Citizenship. In T. Jekel, A. Koller, K. Donert, \& R. Vogler (Eds.), Learning with Geoinformation V - Lernen mit Geoinformation V (pp. 2-11). Berlin: Wichmann.

Gurwitsch, A. (1962). The Common-Sense World as Social Reality - A Discourse on Alfred Schutz. Social Research, 29(1), 50-72.

Haklay, M. (2013). Neogeography and the delusion of democratisation. Environment and Planning A, 45(1), 55-69.

Haklay, M., \& Budhathoki, N. (Producer). (2010). OpenStreetMap - Overview and Motivational Factors. Horizon Infrastructure Challenge Theme Day.

Hennig, S., \& Vogler, R. (forthcoming). User-centred map applications through participatory design: Experiences gained during the "YouthMap 5020" project. Cartographic Journal, issue \& pp. pending.

Hepp, A., \& Krotz, F. (2014). Mediatized Worlds - Understanding Everyday Mediatization. In A. Hepp \& F. Krotz (Eds.), Mediatized Worlds: Culture and Society in Media Age (pp. 1-15). Basingstoke: Palgrave Macmillan.

Jekel, T., Gryl, I., \& Schulze, U. (2015). Education for Spatial Citizenship. In O. Muñiz Solari, A. Demirci, \& J. van der Schee (Eds.), Geospatial Technologies and Geography Education in an Changing World. Geospatial Practices and Lessons Learned (pp. 35-49). Tokyo: Springer Japan.

Jekel, T., Koller, A., \& Strobl, J. (2012). Research-education cooperations for GI in secondary education. In A. Milson, A. Demirci, \& J. Kerski (Eds.), International perspectives on GIS in secondary education (pp. 27-36). New York: Springer.

Leszczynski, A., \& Elwood, S. (2015). Feminist geographies of new spatial media. The Canadian Geographer / Le Géographe canadien, 59(1), 12-28. doi:10.1111/cag.12093 
Pavlovskaya, M., \& Martin, K. S. (2007). Feminism and Geographic Information Systems: From a Missing Object to a Mapping Subject. Geography Compass, 1(3), 583-606. doi:10.1111/j.17498198.2007.00028.x

Shlasko, G. D. (2005). Queer (v.) Pedagogy. Equity \& Excellence in Education, 38(2), 123-134. doi:10.1080/10665680590935098

Shrewsbury, C. M. (1993). What Is Feminist Pedagogy? Women's Studies Quarterly, 21(3/4), 8-16. doi:10.2307/40022001

Steinmann, R., Häusler, E., Klettner, S., Schmidt, M., \& Lin, Y. (2013). Gender Dimensions in UGC and VGI: A Desk-Based Study. GI_Forum - Journal for Geographic Information Science, 2013(1), 355-364.

Steinmaurer, T. (2014). Mediatized Connectivity: Historical Traits of Telephony and Theoretical Considerations about a New Dispositive of Communication. In A. Hepp \& F. Krotz (Eds.), Mediatized Worlds: Culture and Society in a Media Age (pp. 91-106). Houndmills: Palgrave Macmillan.

Strobl, J. (2014). Technological Foundations of the GISociety. In T. Jekel, E. Sanchez, I. Gryl, C. Juneau-Sion, \& J. Lyon (Eds.), Learning and Teching with Geomedia (pp. 2-9). Newcastle upon Tyne: Cambridge Scholars Publishing.

Thielmann, T., van der Velden, L., Fischer, F., \& Vogler, R. (2012). Dwelling in the Web: Towards a Googlization of Space. HIIG Discussion Paper Series No. 2012-03. SSRN: Social Science Research Network. Retrieved from http://ssrn.com/abstract $=2151949$ or http://dx.doi.org/10.2139/ssrn.2151949

Universität Salzburg. (2015). Mitteilungsblatt - Sondernummer der Paris Lodron-Universität Salzburg. 164 Verordnung des Vizerektors für Lehre über die Durchführung pädagogisch-praktischer Themenmodule. Retrieved from http://www.unisalzburg.at/fileadmin/multimedia/Sprachenzentrum/documents/mb150915-vo-ppsthemenmodule.pdf

Vogler, R., Hennig, S., \& Lindner-Fally, M. (2015). Shrinking technical Challenges - Zur strukturierten Erstellung digitaler Karten im Unterricht. GW-Unterricht, 137(1), 49-60.

Wardenga, U. (2002). Räume in der Geographie, Zu Raumbegriffen im Geographieunterricht. Wissenschaftliche Nachrichten, 120, 47-52.

Wastl-Walter, D. (2010). Gender Geographien. Geschlecht und Raum als soziale Konstruktionen. Stuttgart: Steiner.

Webb, L. M., Allen, M. W., \& Walker, K. L. (2002). Feminist Pedagogy: Identifying basic principles. Academic Exchange Quarterly: AEQ, 6, 67-72.

Winker, G., \& Degele, N. (2010). Intersektionalität. Zur Analyse sozialer Ungleichheiten (2., unveränd. Aufl. ed.). Bielefeld: Transcript-Verlag. 